\title{
Sobre interferência sintática em tradução e em escrita autêntica ${ }^{1}$
}

\author{
Madalena Colaço \& Anabela Gonçalves \\ Universidade de Lisboa, Faculdade de Letras, Centro de Linguística
}

\begin{abstract}
:
In translation contexts, translators must activate two distinct grammars, as well as pragmatic conditions that may also be distinct. This particular case of languages in contact may give rise to inadequacies or errors, sometimes explained as the result of transferring properties of the source language to the target language. Focussing on the results presented in Gonçalves \& Colaço (2019), who analysed some issues concerning reference chains in the context of translation, this paper discusses the data under a new perspective. In line with Sorace \& Filiaci's (2006) Interface Hypothesis, we show that in translation, as well as in other situations of languages in contact, linguistic phenomena involving the interface between syntax and other cognitive domains (in particular, semantics and pragmatics) are more affected than phenomena that exempt this interface, which explains why syntactic interference does not operate randomly; we show that this hypothesis is empirically motivated by data involving reference chains in the context of English to Portuguese translation. Plus, we present and discuss data from L1 authentic writing, showing that Portuguese students at the University present similar problems in establishing the adequate reference chains both when they are writing texts in their L1 (Portuguese) and when they are translating from English to their L1 (Portuguese), which leads us to conclude that reference chains are a particular relevant area to confirm the Interface Hypothesis also in L1 contexts.
\end{abstract}

Keywords: syntactic interference, interface areas, reference chains, translation, L1 authentic writing

Palavras-chave: interferência sintática, áreas de interface, cadeias de referência, tradução, escrita autêntica em L1

\section{Introdução}

Numa situação de tradução, o tradutor tem de ativar, em simultâneo, duas gramáticas distintas, bem como condições pragmáticas que poderão ser igualmente distintas. Este contacto entre duas línguas pode gerar erros ou inadequações que, muitas vezes, resultam de transferência de propriedades da língua de partida (LP) para a língua de chegada (LC), no que diz respeito quer a aspetos de natureza lexical quer a aspetos gramaticais e, em particular, sintáticos. Estas situações são comummente referidas nos estudos de tradução (cf. e.o., Baker, 1992; Venuti, 1995; Newmark, 1988; Hatim \& Munday, 2004) e associadas à tradução direta (Vinay \& Darbelnet, 1958), ou seja, àquela em que o tradutor transpõe o texto de partida (TP) elemento a elemento para o texto de chegada (TC). Nestes casos, o tradutor faz uso de diferentes estratégias, de que se destacam o empréstimo, maioritariamente lexical (com a manutenção de expressões do texto de partida), e o decalque (com alguma manipulação das expressões lexicais e dos padrões sintáticos do texto de partida, que aquele traduz literalmente).

A ideia de que o decalque é uma das estratégias que resultam em mais erros ou inadequações é aceite no âmbito dos estudos de tradução e foi também a hipótese que colocámos em Gonçalves \& Colaço (2019), relativamente a problemas na construção de cadeias de referência que envolvem sujeitos pronominais no par linguístico inglês-português. Contudo, nesse trabalho, não apresentámos qualquer explicação para o facto de os

${ }^{1}$ Este trabalho foi desenvolvido no Centro de Linguística da Universidade de Lisboa (CLUL), financiado pela Fundação para a Ciência e a Tecnologia (UID/LIN/00214/2019). 
estudantes manifestarem dificuldades nestas estruturas em particular, pelo que não distinguimos os problemas de construção de cadeias de referência dos casos de empréstimos lexicais e decalques morfológicos, que surgem, maioritariamente, de forma aleatória (cf. Cardinaletti, 2004).

No que diz respeito aos chamados decalques sintáticos, nem sempre se obtém na literatura uma explicação para o facto de esta estratégia ser usada em certas estruturas e não noutras. Neste âmbito, destacam-se os trabalhos de Cardinaletti $(2004,2012)$ e de Giusti (2004), que, analisando traduções que envolvem o par inglês-italiano, e centrando-se em aspetos relacionados com o sujeito e a referência nominal, defendem que as áreas mais problemáticas na tradução são as que exigem a articulação entre várias componentes, nomeadamente a sintaxe e as componentes interpretativas que integram o sistema cognitivo (a semântica e a pragmática).

No presente trabalho, são nossos objetivos:

(i) Retomar dados sobre o sujeito em traduções feitas por estudantes universitários (Gonçalves \& Colaço, 2019), analisando-os à luz das propostas de Cardinaletti (2004, 2012) e Giusti (2004) para o par inglês-italiano, no sentido de confirmar que os problemas na construção de cadeias de referência no caso do par inglês-português não surgem de forma aleatória, resultando, antes, do facto de a interferência sintática operar sobre estruturas em que a sintaxe interage com as componentes do sistema cognitivo.

(ii) Mostrar que a tradução é um contexto que, por envolver o contacto de línguas, é semelhante a outros contextos de contacto linguístico, como os de aquisição bilingue, aquisição de L2 ou erosão linguística, como os estudados, entre outros, por Sorace $(2000,2002,2003,2005,2011)$ e Sorace \& Filiaci (2006), o que confirma a ideia de que estruturas que envolvem interface de diferentes componentes apresentam maiores problemas de produção e interpretação em situações em que estão envolvidas as gramáticas de duas línguas. No caso da tradução, porque as duas gramáticas são ativadas (quase) em simultâneo, a interferência linguística poderá ser potenciada.

(iii) Apresentar e discutir dados de escrita autêntica em L1 de estudantes do ensino superior (cf. Cardoso \& Magro, 2013; Cardoso et al., 2014), no sentido de mostrar que estes manifestam problemas idênticos aos dos estudantes de tradução cujos dados apresentámos em Gonçalves \& Colaço (2019), o que permitirá confirmar que a construção de cadeias de referência é um campo particularmente fértil para a confirmação da hipótese de interface. Os dados de produção escrita autêntica permitir-nos-ão, ainda, mostrar que alguns dos problemas quanto à construção de cadeias de referência podem transcender os fenómenos de interferência sintática.

O trabalho organiza-se da seguinte forma: na secção 2, apresentam-se sumariamente os resultados de alguns estudos que têm mostrado a emergência de fenómenos de interferência linguística em situações de contacto de línguas, com destaque para a tradução, que servem de base à retoma dos dados de L2 apresentados em Gonçalves \& Colaço (2019), relacionados com questões de coesão referencial provocadas por usos inadequados de certas formas anafóricas na posição de sujeito; na secção 3, é apresentado um conjunto de dados retirados de textos de L1 nos quais, apesar de não se colocar a questão do contacto linguístico, se verificam diversos problemas igualmente relacionados com a coesão referencial; na secção 4, é feita uma comparação entre os dados obtidos em textos traduzidos e os dados de textos autênticos em L1, que aponta no sentido de que, em qualquer dos casos, a área da interface entre a sintaxe e as componentes interpretativas é uma área vulnerável, o que conduz a frequentes hesitações, dúvidas ou mesmo impropriedades por parte dos falantes; finalmente, na secção que termina este trabalho, são apresentadas algumas conclusões e sugeridas algumas pistas para desenvolvimentos futuros. 


\section{A tradução como uma situação de contacto de línguas: vulnerabilidade e erosão linguística}

Alguns estudos - veja-se Frawley (1984), Baker (1993, 1996), Toury (1995), entre outros - têm sugerido a existência de características específicas nos textos traduzidos - uma espécie de padrões ou tendências "universais" - que permitem diferenciá-los dos textos autênticos escritos na língua nativa, mesmo em situações em que os tradutores são falantes nativos da língua para a qual traduzem. Com efeito, num contexto de tradução, o tradutor não produz o texto de uma forma autónoma, dado que está limitado ao texto de partida quer em termos de conteúdo quer no que diz respeito aos aspetos formais. A presença de características específicas nos textos traduzidos tem sido encarada por alguns autores como o resultado de uma situação particular de contacto de línguas, uma vez que, durante o processo de tradução, há duas línguas que estão em contacto na mente do tradutor, sendo as gramáticas de ambas necessariamente ativadas em simultâneo.

\subsection{Interferência linguística em traduções de inglês para italiano}

Em Cardinaletti (2004), defende-se a ideia de que algumas características sintáticas inovadoras que se verificam em textos traduzidos de inglês para italiano - concretamente, relacionadas com o sistema pronominal - resultam de um fenómeno de interferência da LP na LC. No caso concreto em estudo, a interferência verificada no italiano resulta, nas palavras da autora, numa espécie de relaxamento das restrições à ocorrência da forma pronominal realizada, no sentido em que são produzidas formas realizadas em contextos em que é mais frequente a forma nula, por influência da LP, que não admite formas pronominais nulas. Veja-se (1), em que b. corresponde a uma tradução do inglês, na qual se verifica a realização do pronome através da forma loro, e em c. se mostra que este pronome foi realizado num contexto que permite (e em que é mais adequada) uma forma nula:

(1) a. if it got out that they were related to a pair of - well, (...) $(H P, 11)$.

b. se $\varnothing$ veniva fuori che loro erano parenti di una coppia di... be' $(\ldots)(H P, 11)$.

c. se $\varnothing$ veniva fuori che $\varnothing$ erano parenti di una coppia di... be' (...).

[Cardinaletti, 2004: 138]

Esta interferência não chega a provocar a produção de frases agramaticais. No entanto, este fenómeno pode dar origem a frases inapropriadas para um determinado contexto, uma vez que a realização do sujeito num contexto que permite sujeito nulo pode provocar redundância ou mesmo induzir uma interpretação diferente daquela que se pretende.

De acordo com a autora, contrariamente ao que acontece relativamente a aspetos lexicais ou morfológicos, a interferência sintática não ocorre de forma aleatória, verificando-se especialmente em áreas de interface entre a componente sintática e as componentes interpretativas, aquelas em que se verifica a integração entre a sintaxe e o sistema cognitivo (nomeadamente, a semântica e a pragmática). Assim, como é referido em trabalho posterior da autora, em Cardinaletti (2012), esta interferência resulta sobretudo na presença de um maior leque de opções para o tradutor do que para o produtor de um texto espontâneo, por influência da LP.

A análise proposta por Cardinaletti (2004) parte da consideração já referida acima de que o contexto da tradução é um contexto de contacto de línguas, em que, tipicamente, o tradutor traduz para a sua língua materna a partir de uma língua na qual possui um elevado grau de proficiência. Neste sentido, este contexto é semelhante a outras situações de contacto de línguas, nas quais se regista o mesmo fenómeno de interferência.

Com efeito, Sorace \& Filiaci (2006), partindo de Sorace (2000, 2003, 2005), entre outros, mostram que, em contextos de aquisição bilingue, de aquisição de L2 e de erosão linguística, as estruturas gramaticais em que se verificam problemas residuais da L1, indeterminação e opcionalidade são, geralmente, aquelas que envolvem a interface entre a sintaxe e o sistema cognitivo, não havendo, na generalidade, evidência para opcionalidade naqueles contextos, no que diz respeito a propriedades sintáticas em sentido estrito. De acordo com as autoras, 
esta generalização está na base da hipótese de que propriedades gramaticais que envolvem apenas a sintaxe são adquiridas completamente numa L2, mesmo que se registem atrasos de desenvolvimento relativamente aos falantes que a adquirem como L1, e que propriedades que envolvam interface com outras componentes podem não ser totalmente adquiridas. Esta hipótese, que Sorace \& Filiaci (2006) cunharam como "Hipótese da Interface" (Interface Hypothesis, HI), encontra suporte empírico na sintaxe dos sujeitos pronominais (logo, por extensão, na construção de cadeias de referência), que as autoras consideram ser particularmente relevantes para a avaliação da HI, uma vez que o domínio dessas formas em diferentes línguas é condicionado por fatores de natureza distinta (cf. também Sorace, 2000; Lobo \& Silva, 2016; Silva, 2015, 2018, e.o.): sintáticos (p.e., posição dos antecedentes), morfossintáticos (p.e., formas nulas vs. formas realizadas), semânticos (p.e., interpretação das formas nulas e das formas plenas; impacto dos traços semânticos associados às formas pronominais, como o traço de animacidade), discursivos ou pragmáticos (p.e., continuidade ou mudança de tópico, efeitos de foco). No âmbito da aquisição de pronomes no contexto de aprendizagem de PE como LE, Madeira, Xavier \& Crispim (2012), num trabalho sobre produção e interpretação de sujeitos pronominais em contextos não matriz, mostram que aprendentes de PE cuja língua materna é o chinês apresentam mais dificuldades com sujeitos realizados, o que as autoras atribuem ao facto de este tipo de sujeitos envolverem mais custos de processamento, o que poderá resultar em desenvolvimento mais tardio; tal hipótese está também alinhada com os trabalhos de Sorace, pelo menos no que diz respeito aos aprendentes chineses. ${ }^{2}$

Também Giusti (2004) tratou a interferência sintática resultante de situações de contacto de línguas, baseando-se na análise da tradução para italiano dos primeiros dois volumes de Harry Potter, de J. K. Rowling, com especial atenção para a questão da posição do sujeito. O trabalho desta autora partilha com o de Cardinaletti (2004) o objetivo de compreender o alcance deste tipo de interferência e de perceber se, inclusivamente, a interferência pode dar origem a mudança linguística (ou aceleramento de mudança linguística em curso) na LC por influência das características da LP. Tal como Cardinaletti (2004), também Giusti (2004) conclui que a interferência sintática é, usando as suas palavras, um processo "marginal" do sistema linguístico, que afeta zonas periféricas (e não zonas centrais) da gramática do falante, no sentido em que resulta em produções que não são completamente (ou consensualmente) aceitáveis num determinado contexto, embora não sejam agramaticais. Assim, os resultados do estudo efetuado pela autora mostraram a existência de interferência do inglês no italiano relativamente à posição do sujeito, manifestada na ocorrência de sujeitos pré-verbais em contextos em que, em italiano, a sua posição é tipicamente pós-verbal. Este fenómeno está ilustrado em (2), em que b. corresponde a uma frase retirada de um texto traduzido, em que o sujeito é colocado numa posição pré-verbal, tal como na frase correspondente do texto de partida, enquanto c. corresponde a uma frase equivalente produzida de acordo com a gramática do italiano, em que o sujeito ocorre em posição pós-verbal:

(2) a. Seconds later, a bell clanged, and Malfoy stepped into the shop (ChS 42).

b. Un attimo doppo un campanello suonò e Malfoy entrò nel negozio (CS 48).

c. Un attimo doppo suonò un campanello e Malfoy entrò nel negozio.

[Giusti, 2004: 156]

Trata-se, mais uma vez, de um fenómeno que não afeta propriamente a gramaticalidade das frases, mas que conduz, por vezes, a violação de princípios informacionais e interpretativos. Também Sorace $(2000,2002)$ registou o mesmo fenómeno de alteração da posição do sujeito em falantes italianos quase nativos de inglês.

\footnotetext{
${ }^{2}$ A Hipótese da Interface tem sido alvo de debate. Com efeito, se alguns trabalhos sobre L2 oferecem evidência para a mesma, outros têm apresentado argumentos que a colocam parcialmente em causa. Para uma visão sobre este debate, ver Teixeira (2016). Crucialmente, o que nos interessa reter da HI é que a interface entre a sintaxe e os sistemas cognitivos apresenta desafios para a aquisição de L2, como afirma Teixeira (2016). Não discutiremos aqui os termos em que a HI deverá ser reformulada nas suas predições específicas.
} 
No entanto, também neste caso, o facto de estes falantes continuarem, ainda assim, a usar sujeitos pós-verbais em italiano mostra que, na sua gramática, esta propriedade não está afetada.

Cardinaletti (2005), retomando trabalhos anteriores, introduz a ideia de que a interferência sintática observada no contexto da tradução pode resultar num fenómeno de atrito ou erosão (ou seja, modificação parcial) da LC (ou seja, em princípio, a língua nativa do tradutor) semelhante ao que se verifica noutras situações em que um falante com uma competência quase nativa numa língua estrangeira (L2) tem um contacto prolongado com essa língua, provocando esse contacto modificações na gramática da sua língua materna. Desta forma, remetendo para os trabalhos de Weinreich (1953) e de Gusmani (1981), a autora aproxima a interferência sintática resultante da atividade tradutória da interferência que vários estudos têm mostrado existir, por exemplo, em contextos que envolvem situações de bilinguismo. O estudo realizado por Cardinaletti (2005), focado na sintaxe do sujeito, reforçou as conclusões obtidas em Cardinaletti (2004), mostrando que, no contexto da tradução de inglês para italiano, a distribuição dos pronomes realizados lexicalmente é afetada, verificandose o uso de formas pronominais em contextos diferentes daqueles em que tipicamente ocorrem.

No entanto, os dados mostraram que esta alteração tem uma natureza facultativa, uma vez que o uso de pronomes nulos pelos tradutores italianos se mantém intacto, ou seja, os tradutores continuam a usar pronomes nulos, não optando sistematicamente por formas realizadas. Este facto é observável em (3), em que, no excerto traduzido ilustrado em b., coexiste o uso adequado de formas nulas com o uso inadequado de uma forma realizada:

(3) a. He'd never been more nervous, never, not even when he'd had to take a school report home to the Dursleys saying that he'd somehow turned his teacher's wig blue ( $\mathrm{PhS}, 86)$.

b. Ø Non era mai stato nervoso in vita sua, mai, neache quando $\boldsymbol{\varnothing}$ era tornato a casa con una nota della scuola in cui diceva che, non si sa come, lui aveva fatto diventare blu la parrucca dell'insegnante $(\mathrm{PhS}, 111)$

[Cardinaletti, 2005: 61]

A alteração na distribuição dos pronomes foi pela autora interpretada como um fenómeno de erosão linguística, que resulta, como já foi referido atrás, de uma espécie de relaxamento das restrições pragmáticas sobre a utilização das formas realizadas. Assim, este trabalho reforçou, na linha dos anteriores, a hipótese de que nem todos os fenómenos gramaticais estão sujeitos a erosão, sendo a interferência um processo muito seletivo. A erosão verifica-se fundamentalmente no que diz respeito a aspetos relacionados com a zona mais "marginal" ou "vulnerável" da gramática, ou seja, com os níveis de interface, nos quais se estabelece a ligação da sintaxe com aspetos interpretativos, nomeadamente semânticos e pragmáticos.

Numa tentativa de analisar conjuntamente os fenómenos de erosão resultantes do contacto de línguas como os descritos anteriormente, Cardinaletti (2005) retoma a hipótese de Sorace (2000), sugerindo a existência de uma relação entre os aspetos gramaticais sujeitos ou não a interferência e a natureza dos traços envolvidos nas operações sintáticas, de acordo com os pressupostos do programa minimalista (na versão de Chomsky, 1995), no qual é estabelecida uma distinção entre propriedades estritamente sintáticas, ou não interpretáveis, e propriedades interpretáveis, ou seja, relevantes para a componente semântica. De acordo com Sorace (2000), apenas os traços interpretáveis estão sujeitos a erosão linguística, uma vez que apenas os níveis de interface são afetados, razão pela qual, normalmente, a erosão dá origem a violações de princípios interpretativos e não a agramaticalidades. Assim, para esta autora, a passagem de sujeitos tipicamente pós-verbais para a posição pré-verbal em italiano é explicável a partir da não especificação do traço [+tópico] tipicamente associado aos sujeitos pré-verbais nesta língua. Na mesma linha de pensamento, a influência do inglês no italiano no que diz respeito às formas pronominais utilizadas é analisada por Cardinaletti (2005) como o resultado da perda de um traço interpretável [+referencial] dos pronomes realizados em italiano, por influência do inglês: dado o facto de 
o inglês ser uma língua com pronomes realizados fortes (a que a autora atribui o traço [+referencial] e que podem ser referencialmente autónomos) e pronomes realizados fracos (que a autora considera não terem este traço e que são sempre interpretados anaforicamente), os pronomes realizados do italiano, que, à partida, são sempre fortes, tornam-se, facultativamente, fracos, deixando de ser especificados quanto ao traço [+referencial]. Assim, como resultado desta reanálise, ocorrem, nos textos traduzidos para italiano, pronomes realizados que, para os tradutores, não estão associados a este traço.

Se, por um lado, de acordo com as autoras acima mencionadas, noutros casos de contacto de línguas prolongado, a interferência da L2 na L1 pode conduzir a uma modificação parcial da competência na L1, a questão tem contornos específicos no caso da tradução, uma vez que a relação do tradutor com a LP pode ser muito variável. No entanto, Cardinaletti (2005) sugere a hipótese de que, também neste caso, poderá haver, em casos de contacto sistemático e prolongado com a L2 (ou seja, a língua de partida para a tradução), alterações na gramática da L1 do tradutor, que poderão ser comprovadas através de testes psicolinguísticos de compreensão e de produção que têm sido usados por alguns autores (como Tsimpli et al., 2003) para falantes quase nativos. Esta hipótese tem por base a semelhança que se verifica no que diz respeito aos efeitos de erosão linguística que se verificam nestas diferentes situações de contacto de línguas.

Ora, ao observarmos os dados da tradução inglês-português em Gonçalves \& Colaço (2019), concluímos que o uso de sujeitos pronominais lexicais e nulos é também uma área vulnerável. A confirmação da HI torna mais interessante o trabalho que então apresentámos e em que defendemos que o decalque estaria na base dos dados recolhidos, mas não identificámos a razão pela qual os estudantes usam com frequência tal estratégia em estruturas que envolvem formas pronominais em particular, embora continuem, simultaneamente, a produzir sequências gramaticais e adequadas, mesmo em casos em que as línguas divergem, não recorrendo, nesses casos, ao decalque como estratégia de tradução.

Se atribuirmos os problemas no uso dos pronomes sujeito na tradução à questão da interface entre a sintaxe e o sistema cognitivo, então, ficamos com um quadro uniforme no que diz respeito a contextos de línguas em contacto, ainda que, em cada um deles, os sujeitos/falantes se encontrem em situações distintas. Em particular, no caso da tradução, não se verificam efeitos de aquisição e desenvolvimento, esperando-se, antes, que o tradutor tenha atingido um estado estável quer na LP (nos nossos dados, a sua L2) quer, sobretudo, na LC (nos nossos dados, a sua L1). Sendo a tradução um processo que envolve a ativação simultânea de duas gramáticas, os efeitos preditos pela HI serão, provavelmente, potenciados: é necessário que o tradutor domine, num mesmo momento e para cada língua do par linguístico, a interface entre a sintaxe e os restantes sistemas que caracteriza os sujeitos pronominais.

\subsection{Interferência linguística em traduções de inglês para português}

O estudo preliminar levado a cabo em Gonçalves \& Colaço (2019) sobre os dados do português apresentou dados de escrita recolhidos de traduções envolvendo o par de línguas inglês-português, realizadas em contexto académico por alunos a frequentar o primeiro ano do mestrado em Tradução na Faculdade de Letras da Universidade de Lisboa. Este trabalho centrou-se na questão da (re)construção, no texto de chegada, de cadeias de referência, com especial atenção para as formas pronominais (nulas e com realização lexical) selecionadas pelo tradutor para a posição de sujeito. Estando o tradutor vinculado ao texto de partida em termos de conteúdo e orientado por uma preocupação de fidelidade que o leva, normalmente, a preservar tanto quanto possível as construções que ocorrem nesse texto já construído por outrem, a ocorrência de interferências do texto de partida no texto de chegada era, de certa forma, esperada, sobretudo pelo facto de os sujeitos em questão serem aprendentes e ainda não profissionais de Tradução.

Os dados recolhidos das traduções revelaram essencialmente três tipos de problemas:

(i) Não aplicação da estratégia de minimização da expressão nominal utilizada (cf. Levinson, 1991, 1995; Huang, 1989, 2000) em casos em que tal estratégia é preferida. O excerto apresentado em (4b) ilustra situações 
em que o tradutor usou uma forma pronominal realizada num contexto em que seria adequada a opção por uma forma nula, ou seja, pela forma "mínima". Apesar de cada frase do excerto em português não ter problemas ao nível da gramaticalidade, a realização de pronomes em contextos que permitem formas nulas levanta problemas de redundância, podendo, inclusivamente, criar problemas de ambiguidade referencial. Em (4c), apresenta-se uma sugestão de tradução em que se segue a estratégia da minimização.

(4) a. She had no idea what the hell she was saying. What the hell she was doing. She had never seen so many guns before, much less deliberatly put herself within point-blank range of such weapons - but she had snapped and discovered a surprising surge of power came with the unhinge.

b. Ela não tinha ideia do que estava a dizer. O que raio estava a fazer? Ela nunca tinha visto tantas armas juntas e muito menos se tinha posto deliberadamente no alcance dessas mesmas, mas ela explodiu e descobriu que dela veio uma força enorme.

[Gonçalves \& Colaço, 2019: 139, (83)]

c. Ela não tinha ideia do que estava a dizer. O que raio estava a fazer? Ø Nunca tinha visto tantas armas juntas e muito menos se tinha posto deliberadamente no alcance dessas mesmas, mas $\boldsymbol{\emptyset}$ explodiu e descobriu que dela veio uma força enorme.

[Gonçalves \& Colaço, 2019: 140, (86)]

(ii) Utilização indevida de sujeitos nulos na língua de chegada, impedindo a identificação adequada do antecedente. Na tradução para português apresentada em (5b), a escolha de uma forma nula para o sujeito da oração subordinada adverbial que ocorre no último período de texto não é adequada, uma vez que este sujeito tem um conteúdo proposicional, o que torna a sua realização a solução adequada. Em (5c), apresenta-se uma sugestão de tradução em que o conteúdo proposicional é retomado através de uma expressão nominal com o valor de anáfora conceptual, o problema.

(5) a. If a cat begins showing initial signs of fear, behavior modification can be done in the form of lowintensity interactive playtime for distraction. If caught early, you may be able to change his mindset as you trigger his prey-drive.

b. Se o seu gato começar a apresentar sinais de medo, $\boldsymbol{\varnothing}$ pode alterar o seu comportamento através de brincadeiras interativas pouco energéticas para que ele se possa distrair. Se $\boldsymbol{\emptyset}$ for detetado na fase inicial, Ø pode conseguir alterar a mentalidade do seu gato aos despoletar o seu instinto de caça.

[Gonçalves \& Colaço, 2019: 137, (71)]

c. Se o seu gato começar a apresentar sinais de medo, $\varnothing$ pode alterar o seu comportamento através de brincadeiras interativas pouco energéticas para que ele se possa distrair. Se o problema for detetado na fase inicial, $\boldsymbol{\varnothing}$ pode conseguir alterar a mentalidade do seu gato.

[Gonçalves \& Colaço, 2019: 138, (74)]

A utilização não adequada de formas nulas foi identificada também em contextos em que a ocorrência de um sujeito nulo conduz a uma interpretação diferente da desejada. Em (6b), a escolha de um sujeito nulo para a segunda oração coordenada induz uma leitura de correferência com o sujeito da primeira oração, a família de Dolly, uma vez que esta é a expressão com maior proeminência estrutural, sendo, por isso, o antecedente mais acessível (cf. escala de marcação de acessibilidade proposta em Ariel, 1990, 1996). Na sugestão de tradução apresentada em (6c), a opção por uma forma pronominal realizada na posição de sujeito da segunda oração coordenada permite a retoma do antecedente desejado, Dolly. 
(6) a. Dolly's family immediately doused the raw flesh of her face with water and she was rushed to hospital.

b. A família de Dolly ensopou imediatamente a carne viva da sua cara com água e $\boldsymbol{\varnothing}$ foi rapidamente levada para o hospital.

[Gonçalves \& Colaço, 2019: 138, (75)]

c. A família de Dolly ensopou imediatamente a carne viva da sua cara com água e ela foi rapidamente levada para o hospital.

[Gonçalves \& Colaço 2019: 139, (78)]

(iii) Utilização de anáforas com realização lexical inadequada, com impacto na interpretação. Quando existem dois (ou mais) referentes em competição, como acontece em (7b), o uso do pronome pessoal ele não permite um reconhecimento inequívoco do referente pretendido. Neste contexto, a utilização do pronome demonstrativo este - como se pode ver na sugestão de tradução apresentada em (7c) - permite o reconhecimento do referente a partir da proximidade linear, dado que este pronome estabelece uma relação anafórica com o referente mais próximo.

(7) a. And thus he had not been seriously afraid that Laure would be one of the murderer's victims, since everyone knew that he attacked neither children nor grown women (...)

b. Desta forma, Richis não parecia particularmente preocupado com o facto de Laure poder vir a tornarse uma das vítimas do assassino já que era do conhecimento geral que ele não atacava nem crianças nem mulheres adultas (...).

[Gonçalves \& Colaço, 2019: 140, (89)]

c. Desta forma, Richis não parecia particularmente preocupado com o facto de Laure poder vir a tornarse uma das vítimas do assassino já que era do conhecimento geral que este não atacava nem crianças nem mulheres adultas (...).

[Gonçalves \& Colaço 2019: 141, (91)]

Gonçalves \& Colaço (2019) atribuem alguns dos problemas identificados no que diz respeito à escolha das formas pronominais na posição de sujeito em textos traduzidos (nomeadamente, os referidos em (i)) a uma estratégia de decalque por parte do aprendente de Tradução, que faz com que propriedades de uma das línguas de trabalho sejam transferidas para a língua de chegada. Assim, a opção do tradutor pelo uso de formas pronominais realizadas em contextos em que seria adequada a ocorrência de formas nulas foi atribuída a um fenómeno de transmissão de uma propriedade da língua de partida, o inglês, dado esta ser uma língua que não admite sujeitos nulos. Seguindo as propostas de Cardinaletti (2004, 2005, 2012) e de Giusti (2004), entre outros, esta tendência para o uso excessivo de formas pronominais realizadas poderá ser entendida como o resultado de um fenómeno de interferência linguística, que faz com que o tradutor altere a forma como usa a sua língua materna por influência de uma outra língua. Saliente-se, no entanto, o facto de os dados usados em Gonçalves \& Colaço (2019) corresponderem a produções de estudantes universitários, e não de profissionais de Tradução, cujo grau de proficiência na língua de partida, o inglês, nem sempre poderá ser considerado próximo do de um falante quase nativo, o que poderá fazer com que a questão do contacto de línguas e da interferência linguística adquira contornos específicos.

Por outro lado, os dados apresentados em Gonçalves \& Colaço (2019) mostraram, adicionalmente, que o contacto com uma língua de partida com propriedades distintas no que diz respeito ao sujeito nulo esteve igualmente na origem de um fenómeno, inverso ao anterior, de sobregeneralização da omissão do sujeito (vejam-se os dados apresentados em (5) e em (6)), levando, em certos casos, a uma opção excessiva por formas pronominais nulas, que conduziu frequentemente a situações de ambiguidade ou mesmo impossibilidade de 
determinação do referente. Para além disso, outros casos de uso inadequado de formas pronominais (como ilustrado em (7)) permitiram mostrar a existência, para os autores das produções observadas, de problemas relacionados com a distribuição das expressões referenciais em português, indicando que, eventualmente, esta é uma questão que, pelo menos para aprendentes de Tradução, poderá transcender os fenómenos de interferência linguística resultantes da situação de contacto linguístico que caracteriza o processo tradutório, na linha do que foi referido anteriormente. Este caso em particular, como outros que surgiram no corpus, evidencia não só interferência sintática, que se verifica pelo uso da forma pronominal realizada, mas também alguma dificuldade no uso de demonstrativos, cujas formas distintas estão relacionadas com a proximidade do antecedente.

Colocámos, assim, a questão de saber se estudantes universitários com o mesmo nível de escolarização (com um 1. ${ }^{\circ}$ ciclo completo) manifestariam, em produções escritas na sua L1, problemas com o sistema pronominal e, consequentemente, com a construção de cadeias de referência. Se tal acontecer, os dados de textos autênticos permitem-nos confirmar a HI mesmo em L1. É sobre esta hipótese que refletiremos nas secções seguintes.

\section{A questão da vulnerabilidade no uso da língua materna em contextos de produção escrita (quase) espontânea}

\subsection{A HI em L1}

Ainda que, originalmente, a HI tenha sido colocada com base em dados de aquisição bilingue, de aquisição de L2 e de erosão linguística, ou seja, em contextos de contacto entre duas ou mais línguas, é interessante verificar a sua aplicabilidade também a dados da aquisição de L1. Consideremos, apenas, alguns estudos sobre aquisição do PE.

Trabalhos sobre a aquisição de formas pronominais em PE como L1 têm mostrado igualmente que se trata de uma área vulnerável da gramática. Os resultados de Silva $(2015,2018)$, por exemplo, relativos à interpretação de formas pronominais realizadas e nulas em completivas com indicativo e com conjuntivo, apontam para tendências já descritas para os casos que envolvem L2, como a sobreaceitação de leituras de correferência inadequadas do ponto de vista pragmático, no caso de formas pronominais realizadas, e a aceitação de leituras não preferenciais no caso de sujeitos nulos, particularmente quando ocorrem dois potenciais antecedentes. Perante tais resultados, Silva $(2015,2018)$ conclui que os problemas manifestados pelas crianças na resolução de anáforas decorrem não só da necessidade de a criança de dominar regras sintáticas, conhecimento semântico e informação pragmática, mas também da correta articulação entre estes diferentes níveis linguísticos, o que está em linha com a HI, inicialmente proposta para contextos que envolvem L2.

O trabalho de Lobo \& Silva (2016) chega, no essencial, às mesmas conclusões. As autoras testam também pronomes nulos e realizados em posição de sujeito de frases subordinadas adverbiais. Os resultados mostram, mais uma vez, que os sujeitos nulos estabilizam mais cedo do que os plenos, concluindo as autoras que a resolução de anáforas é uma área de desenvolvimento tardio: "Não é estranho que este fenómeno seja de desenvolvimento tardio, uma vez que se trata de contextos não categóricos, que apresentam variação também na gramática do adulto e que necessitam de integração de informação sintática, semântica e pragmática." (Lobo \& Silva 2016: 332).

Parece, assim, haver convergência quanto a resolução de anáforas na aquisição de L1 e nos contextos de aquisição que envolvem contacto de línguas (como, por exemplo, os descritos nos vários trabalhos de Sorace e de Sorace e colegas, sobre a questão). Com efeito, a instabilidade em contextos de interface deve-se, pelo menos parcialmente, ao processamento ineficaz de estratégias para articular conhecimento sintático e outros tipos de conhecimento. Trabalhos na área do processamento feitos para o português têm também apontado os custos de processamento envolvidos na resolução de anáforas, tendo em conta diferentes fatores, como a posição 
estrutural do antecedente, a respetiva função sintática e efeitos de animacidade. Vejam-se, a título de exemplo, Luegi (2012), Luegi, Costa \& Maia (2014), Hora et al. (2019).

Por sua vez, os dados de Cardoso \& Magro (2013) apontam para o facto de a instabilidade quanto ao estabelecimento de relações de correferência se manter em produções escritas espontâneas de estudantes universitários, candidatos a um $2 .^{\circ}$ ciclo de estudos, com um perfil próximo do dos sujeitos que integraram a amostra de Gonçalves \& Colaço (2019).

Tendo em conta o enunciado, o objetivo da secção seguinte é o de mostrar que, apesar de haver fenómenos que ocorrem particularmente no contexto da tradução, as áreas que são afetadas - nomeadamente, as áreas interpretativas - são áreas vulneráveis também para o contexto da escrita autêntica em L1, em que a seleção das expressões referenciais oferece frequentemente problemas.

\subsection{Dados de produção escrita autêntica em L1}

Alguns trabalhos baseados em dados de escrita autêntica na língua materna têm permitido mostrar que as áreas em que se verifica a interface da sintaxe com as componentes interpretativas são, também neste contexto, áreas particularmente vulneráveis na gramática mental dos falantes. Essa vulnerabilidade reflete-se no uso da língua através de frequentes hesitações, dúvidas ou mesmo impropriedades. Cardoso \& Magro (2013), por exemplo, analisaram um conjunto de 50 textos (cerca de 17500 palavras) correspondentes a artigos de opinião obtidos no âmbito do Projeto CUTe (Corpus of Portuguese Undergraduates' Texts; cf. Cardoso et al., 2014), produzidos por estudantes recém-licenciados, falantes nativos do português, que permitiram identificar diversos problemas relacionados com questões de coesão referencial.

O objetivo do presente estudo é, como já foi mencionado, retomar os dados de Gonçalves \& Colaço (2019) e reanalisá-los à luz das hipóteses colocadas para outras línguas que referimos anteriormente. Para isso, pretendemos avaliar, embora de forma ainda preliminar, o impacto do contexto de contacto de línguas que caracteriza a tradução no comportamento linguístico dos falantes. Assim, confrontaremos os dados apresentados em Gonçalves e Colaço (2019) com os dados analisados por Cardoso \& Magro (2013), de forma a verificar se os aspetos que têm sido atribuídos por autores como Cardinaletti (2004, 2005, 2012) e Giusti (2004) a fenómenos de interferência entre línguas (nomeadamente, a transferência de propriedades da LP para a LC) apresentam, de facto, contornos distintos daqueles que se verificam quando o falante produz um texto autêntico na sua L1.

A análise de Cardoso \& Magro (2013) mostrou que a questão das dependências referenciais e da construção de cadeias de referência constitui, de facto, uma área crítica para os falantes cujas produções escritas foram observadas. Assentando em alguns trabalhos anteriores, as autoras estabeleceram uma tipologia dos problemas identificados, que contemplou os seguintes tipos: (i) inadequação de relação léxico-semântica entre SN anafórico e antecedente (cf. Campos \& Xavier, 1991; Mendes, 2013; Lobo, 2013); (ii) violação da estratégia de minimização da anáfora (cf. Levinson, 1987; Blackwell, 2003); (iii) incompatibilidade de traços morfológicos entre antecedente e anáfora (Lobo, 2013); (iv) uso de pronome ligado a antecedente estruturalmente proeminente (Lobo, 2013); (v) uso de pronome sem antecedente legítimo; (vi) uso de pronome nulo com antecedente proposicional; (vii) uso de pronome nulo ligado a antecedente sem proeminência estrutural (Lobo, 2013); (viii) incompatibilidade de traços semânticos entre antecedente e anáfora.

Nesta secção, apresentaremos os tipos de problemas considerados em Cardoso \& Magro (2013), centrando-nos naqueles que consideramos relevantes para o presente estudo, que envolve a observação das expressões nominais com a função sintática de sujeito. Para este efeito, procedemos à recolha de dados do corpus exemplificativos de cada um dos referidos tipos. Apresentaremos também outros tipos de problemas que identificámos igualmente nos dados do corpus e que nos pareceram interessantes para a discussão desta questão. 
(i) Inadequação de relação léxico-semântica entre SN anafórico e antecedente (cf. Campos \& Xavier, 1991; Mendes, 2013; Lobo, 2013; apud Cardoso \& Magro, 2013)

Como é referido, por exemplo, em Lobo (2013), a interpretação anafórica implica a compatibilidade semântica entre a expressão usada com valor anafórico e o seu antecedente. Em dados como os apresentados em (8) e (9), verifica-se a retoma da referência através de expressões nominais plenas cujos traços semânticos não são compatíveis com os do antecedente. Assim, veja-se (8), em que a expressão este novo acordo é usada indevidamente para retomar a referência da expressão o novo estatuto e ética escolar. Da mesma forma, em (9), a expressão estas atitudes não é semanticamente adequada para retomar a expressão filmagens que mostram a violência de alguns jovens (ou, alternativamente, a expressão a violência de alguns jovens).

(8) O novo estatuto do aluno e ética escolar "vai de encontro" ao que Diez afirmou pois, ao responsabilizar os pais pelos actos/atitudes dos seus educandos, tal como se pode verificar, $\left.\right|^{10}$ através do excerto apresentado “... implicar a instauração de contraordenações aos pais ou encarregados de educação...", faz com que estes comecem a tomar consciência do seu dever enquanto pais, assim como, "obriga-os" a terem um papel mais activo e presente no percurso escolar do seu educando, o que por conseguinte resultará em melhores resultados.

Por este e outros motivos, estou a favor deste novo acordo (...).

[CUTe, F04]

(9) Em terceiro lugar, ainda este ano foram divulgadas filmagens que mostram a violência de alguns jovens. Estas atitudes mostram desrespeito pelos colegas, tanto por parte do aluno que agride como por aquele que grava.

[CUTe, F17]

(ii) Violação da estratégia de minimização da anáfora (cf. Levinson, 1987; Blackwell, 2003; apud Cardoso \& Magro, 2013)

Alguns autores procuram explicar o uso das expressões referenciais propondo a existência de uma relação entre a distribuição das anáforas e aspetos de natureza pragmática. São exemplo deste modelo pragmático vários trabalhos de Huang, como o de (1989) e o de (2000), que vão na linha dos princípios conversacionais de Grice (1989). Assim, por exemplo, de acordo com Huang (2000), a seleção da forma das anáforas articula-se com estratégias pragmáticas como as que foram propostas por Levinson (1987, 1991, 1995), nomeadamente a estratégia da minimização, já referida atrás: é necessário que o referente seja reconhecido, mas deve ser utilizada a forma mínima que permita esse reconhecimento. $\mathrm{O}$ uso desta estratégia implica, então, por exemplo, que contextos que permitem formas nulas, sem problemas de reconhecimento do referente, tornem inadequada a opção por formas realizadas.

Nos dados que se apresentam em seguida, esta estratégia não é usada - verificando-se a retoma por uma expressão nominal plena ou por um pronome -, o que dá origem a redundância:

(10) Sendo que os pais têm em qualquer caso responsabilidade pelas crianças, penso que sempre que se justificar, os pais devem ser responsabilizados pelo comportamento dos filhos.

[CUTe, F19]

(11) A disciplina torna-se, assim, um problema que necessita de ser resolvido o mais rapidamente possível, pois esta implica valores como a tolerância, respeito, entre outros, que ajudam a melhorar a competência social, que é essencial para se viver em sociedade.

[CUTe, F43] 
(iii) Incompatibilidade de traços morfológicos entre antecedente e anáfora (Lobo, 2013; apud Cardoso \& Magro, 2013)

A leitura anafórica implica uma coincidência de valores de traços morfológicos - de pessoa, de género e de número - entre a anáfora e o seu antecedente, particularmente nos casos em que a anáfora é pronominal. A ausência desta coincidência dificulta o estabelecimento da cadeia de referência, podendo mesmo impedi-la, colocando problemas de interpretação e de coesão referencial. Os dados que se seguem apresentam problemas que resultam da não observância desta condição.

Assim, em (12) e (13), é possível observar a ocorrência de problemas, notados em Cardoso \& Magro (2013), provocados pelo uso de formas anafóricas realizadas em que se verifica uma falta de coincidência de valores de traços morfológicos com o antecedente no que diz respeito ao valor de número.

(12) Corremos o risco de o encarregado de educação não cumprir com o seu dever de educar na vida escolar do seu educando, instaurando-se as contra ordenações. Estes têm que perceber que tem que haver um trabalho continuo entre a escola e o trabalho e se o seu educando não o cumprir, terá sérias dificuldades em assimilar da sua maneira, a matéria lecionada.

[CUTe, F10]

(13) Talvez só assim os comecem a apoiar mais no sentido de atingirem o sucesso escolar e, quem sabe, consciencializá-los a respeitárem de verdade a figura de autoridade que encontram dentro da sala de aula, não porque é, pura e simplesmente, essa figura de autoridade dentro da escola mas sim porque é uma das figuras que auxilia, quando é da vontade do aluno, a que estes atingam o sucesso tanto escolar como pessoal e, futuramente, também profissional.

[CUTe, F27]

Adicionalmente, os dados que apresentamos em (14) e (15) mostram que o mesmo tipo de problema pode envolver expressões anafóricas nulas. Em ambos os casos, a morfologia verbal permite a identificação da presença de sujeitos nulos plurais, em contextos em que o antecedente pretendido é singular.

(14) De acordo com o novo Estatuto do Aluno, o encarregado de educação passa a ter responsabilidade relativamente às faltas injustificadas dos filhos, pois $\underline{\boldsymbol{\Phi}}$ poderão ter coimas.

[CUTe, F17]

(15) Há, de facto, situações de indisciplina, mas, muitas vezes, são motivadas pela desmotivação do aluno face ao que lhe é imposto $\boldsymbol{\varnothing}$ aprenderem e a forma como $\boldsymbol{\varnothing}$ aprendem.

[CUTe, F34]

(iv) Uso de pronome sem antecedente legítimo (Cardoso \& Magro, 2013)

O problema que se regista no dado que podemos observar em (16) foi classificado por Cardoso \& Magro (2013) como correspondendo a uma situação em que um pronome é usado anaforicamente, mas em que não existe um antecedente legítimo, no sentido em que não existe, no interior da sequência textual, uma expressão com a qual o pronome mantenha uma relação de correferência.

(16) Por tudo isto, na minha opinião, as novas medidas não solucionam os problemas em questão. Os

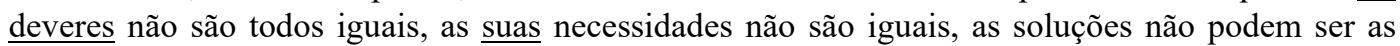
mesmas para todos.

[CUTe, F35] 
Note-se que, para além do contexto considerado pelas autoras, em que o pronome anafórico tem realização lexical, encontrámos no corpus alguns dados que mostram que este tipo de problema se verifica também em contextos em que o pronome anafórico é nulo, neste caso um sujeito nulo. Em (17), a interpretação do sujeito nulo assinalado não é possível, dado não existir um antecedente que permita fixar anaforicamente a sua referência. Note-se que, neste caso, ocorrendo como sujeito de um segundo termo coordenado, este pronome nulo poderia estabelecer uma relação de correferência com o sujeito do primeiro termo, mas não é, obviamente, essa a interpretação pretendida.

(17) É cada vez mais fundamental envolver estes dois ambientes, escola e família, na busca de um desenvolvimento educativo harmonioso. Não esquecer que o percurso de desenvolvimento de qualquer pessoa não acontece apenas dentro da escola. $\mathrm{O}$ ambiente familiar também tem um papel preponderante e daí $\underline{\emptyset}$ dever ser chamado à responsabilidade pelos comportamentos do seu educando.

[CUTe, F49]

\section{(vii) Uso de pronome nulo sem antecedente no texto}

Para além dos contextos descritos anteriormente, em que são usadas formas pronominais anafóricas sem um antecedente legítimo, encontrámos ainda, no corpus, alguns casos em que ocorrem sujeitos nulos anafóricos sem qualquer antecedente no texto. É o que se verifica em (18) e (19). Note-se que, apesar de, em ambos os casos, ocorrerem formas verbais de terceira pessoa do plural, não se trata de construções impessoais em que o sujeito tem uma interpretação arbitrária. Pelo contrário, o sujeito, embora nulo, é referencial, pois é usado para referir uma entidade plural específica: as pessoas que fizeram a lei. Simplesmente, não ocorre, no texto, nenhuma expressão nominal que refira essa entidade e que possa, assim, servir de antecedente.

(18) Assim, se desde o principio houver a preocupação em cuidar de uma criança, incutindo-lhe as regras necessárias para viver em sociedade, serão evitados comportamentos que envolvam indisciplina. Ao $\underline{\varnothing}$ penalizarem os alunos com faltas normais sempre que não tenham material, incutem aos jovens o sentido de responsabilidade.

[CUTe, F19]

(19) Como conclusão, acho que a lei tem coisas boas e más, mas $\underline{\emptyset}$ deveriam ter muito mais atenção e cuidado no bem estar do aluno.

[CUTe, F41]

(v) Uso de pronome nulo com antecedente proposicional (Cardoso \& Magro, 2013)

O uso de um pronome nulo com antecedente proposicional foi considerado por Cardoso \& Magro (2013) como um dos tipos de problemas identificados nos textos analisados. Este problema pode ser observado em dados como (20) e (21).

(20) Apesar de aceitar que na sociedade em que vivemos os pais estarem cada vez mais preocupados com a sua vida profissional, considero que $\underline{\varnothing}$ não é justificação suficiente para que os pais não se comportem como tal, influenciando o futuro das crianças.

[CUTe, F19]

(21) Cada vez mais se assiste à perda de importância da escola na vida dos alunos, à falta de respeito para com os colegas, professores e auxiliares, e à ausência dos encarregados de educação na vida escolar dos alunos, com isto, os próprios alunos perdem também eles o interesse, a vontade de aprender e de cumprir o que lhes é solicitado, uma vez que em casa não se dá importância aos estudos, não se 
valoriza uma boa nota ou um bom comportamento e se por outro lado não se pune um mau resultado ou mau comportamento, então $\underline{\varnothing}$ deixa de fazer sentido para as crianças.

[CUTe, F42]

(vi) Uso de pronome nulo ligado a antecedente sem proeminência estrutural (Lobo, 2013; apud Cardoso \& Magro, 2013)

A existência de uma relação estreita entre a seleção das formas anafóricas e aspetos de natureza estrutural é reconhecida por diversos autores. Hinds $(1978,1979)$ e Fox (1987), por exemplo, defendem um modelo de hierarquia, no qual se estabelece uma relação direta entre a organização do discurso e a seleção das expressões referenciais. Por sua vez, Ariel $(1990,1996)$ desenvolve uma teoria sobre a distribuição das anáforas que se baseia na relação que se estabelece entre a forma das anáforas e a proeminência do antecedente, estabelecendo uma escala - escala de marcação de acessibilidade (accessibility marking scale) - que correlaciona estes dois fatores: quanto mais acessível estiver o antecedente, mais reduzida será a forma anafórica utilizada. Assim, a ocorrência de anáforas nulas adequa-se a contextos em que o referente é proeminente, estando, por isso, muito acessível, enquanto as expressões nominais plenas são favorecidas por contextos em que o referente, não sendo proeminente, está pouco acessível. Também Lobo (2013), Luegi (2012), Luegi, Costa \& Maia (2014) e Hora et al. (2019) referem a proeminência estrutural, relacionada com a função sintática desempenhada pelas expressões, como um fator determinante para o estabelecimento de relações referenciais, mais concretamente, para a existência de correferência, aspeto este que é assinalado em Cardoso \& Magro (2013).

A retoma da referência em contextos em que o antecedente não é uma expressão proeminente obriga frequentemente à seleção de formas realizadas, pelo que a ocorrência de pronomes nulos não é adequada nesses contextos.

Em (22), o sujeito nulo assinalado tem como antecedente pretendido uma expressão nominal - os alunos - que ocorre no interior do sujeito da frase, não sendo, portanto, um antecedente acessível dado não se tratar de uma expressão estruturalmente proeminente. Assim, neste contexto, verifica-se uma inadequação no que diz respeito à escolha da forma anafórica usada, dado que a referência deveria ser retomada através de uma forma realizada.

(22) Muitas decisões dos alunos acabam por ser tomadas insconscientemente só para $\underline{\emptyset}$ não serem mal vistos pelos seus colegas e não serem excluídos do grupo.

[CUTe, F11]

Como foi igualmente apontado por Cardoso \& Magro (2013), existem dados no corpus observado que mostram o uso inadequado de pronomes anafóricos nulos para retomar outras expressões não proeminentes, como acontece em (23), em que o sujeito nulo assinalado tem como antecedente pretendido uma expressão que ocorre encaixada no objeto direto da frase matriz, ou como acontece também em (24), em que o antecedente pretendido ocorre encaixado num tópico marcado lexicalmente.

(23) Segundo este novo Estatuto, proposta de lei nº255/2012, de 31 de Maio de 2012, prevê-se uma maior integração dos alunos menos disciplinados na comunidade, $\underline{\varnothing}$ desenvolvendo trabalho comunitário como sanção, bem como, trabalho de grupo na escola com acompanhamento de professores e/ou médicos especializados e psicólogos, deixando o "castigo" de desenvolverem trabalhos individuais.

[CUTe, F37]

(24) No segundo ponto, no que diz respeito a disciplina por parte dos alunos, em relação a professor e restante comunidade escolar $\underline{\varnothing}$ terá vindo a ser esquecida.

[CUTe, F46] 
Para além destes contextos de inadequação da forma anafórica, a observação do corpus permitiu-nos identificar mais duas situações do mesmo tipo: o uso de um sujeito nulo anafórico em frases em que o antecedente ocorre encaixado numa expressão parentética - ilustrado em (25) - e em frases em que o antecedente está encaixado no complemento oblíquo de uma subordinada adverbial em posição inicial e clivada - ilustrado em (26).

(25) É necessário que seja concedido ao professor um maior poder na decisão de alguns casos, como é o caso de um professor que seja vitima de algum aluno, $\underline{\varnothing}$ pode pedir transferência do aluno abusivo para outra turma, de forma a contornar algumas situações problemáticas.

[CUTe, F06]

(26) No meu ponto de vista, não concordo totalmente com esta medida, considerando que o aluno poderá ser punido, mas em vez de apenas uma falta de material serem dadas duas ou três oportunidades, como aconteceu anteriormente, em que só quando o aluno chegasse ao limite das três faltas de

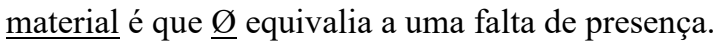

[CUTe, F24]

\section{(ix) Uso de pronome demonstrativo com antecedente não pretendido}

A observação dos dados recolhidos do corpus permitiu-nos constatar a recorrência de problemas, por parte dos sujeitos, no que diz respeito à construção de cadeias de referência usando pronomes demonstrativos, pelo que acrescentámos à tipologia considerada em Cardoso \& Magro (2013) este tipo de problema.

$\mathrm{O}$ uso de diferentes formas dos pronomes demonstrativos permite a criação de diferentes relações referenciais, dado que a correferência se pode estabelecer, em função das formas escolhidas, com um antecedente mais distante ou mais próximo em termos lineares (sobre cadeias de referência que incluem pronomes demonstrativos em português, ver, entre outros, Oliveira, 1987; Figueiredo, 2000 e Silva, 2001). Os exemplos (27) e (28) ilustram alguns problemas relacionados com o uso destas formas pronominais.

Em (27), o uso da forma esses implica que a correferência se estabeleça não com a expressão nominal mais próxima, mas com uma outra mais distante em termos lineares. Assim, neste caso, o antecedente do demonstrativo será pais, embora o antecedente pretendido seja os seus filhos.

(27) Há casos de pais que se preocupam e acompanham o percurso escolar dos seus filhos, contudo, esses continuam a cometer atos de indisciplina e de mau comportamento.

[CUTe, F07]

O dado apresentado em (28) ilustra a situação inversa: a escolha da forma demonstrativa estes implica uma relação de correferência com a expressão nominal mais próxima - neste caso, os filhos -, quando o antecedente que se pretende é a expressão menos próxima os pais ou encarregados de educação.

(28) Eu, pessoalmente, não concordo com esta afirmação, pois penso que os pais ou encarregados de educação têm responsabilidades na educação objetiva dos filhos. São estes que têm a obrigação de lhes incutir valores e princípios.

[CUTe, F47]

Observando conjuntamente os dados recolhidos do corpus considerado e analisando os problemas referidos nesta secção, podemos verificar que, ao usar a sua língua materna em contexto de produção de texto autêntico, os sujeitos mostraram claramente a sua dificuldade, por um lado, na identificação das condições que 
determinam a diferença entre a ocorrência de expressões pronominais nulas e expressões pronominais realizadas, e, por outro lado, na escolha das formas pronominais anafóricas realizadas que são adequadas a cada contexto, no sentido de permitirem ao leitor do texto a interpretação pretendida. Estes dados permitem-nos, pois, fundamentar a ideia de que a área em que se estabelece a interface entre a sintaxe e a componente interpretativa é também uma área vulnerável no que diz respeito ao uso espontâneo da língua materna.

\section{Tradução e produção espontânea na língua materna}

Quando se compara os dados recolhidos das traduções por Gonçalves \& Colaço (2019) com os dados de escrita autêntica em L1, conclui-se que o estabelecimento de correferência é, em ambos os casos, problemático: em particular, verificam-se dificuldades na manipulação de expressões anafóricas que veiculem o sentido pretendido, muitas vezes por terem como antecedente uma expressão inadequada ou que não é o antecedente preferencial. ${ }^{3}$ Esta observação permite-nos defender que as expressões anafóricas (em posição de sujeito) são uma área vulnerável da gramática não só em situações de contacto entre línguas (cf. os diferentes trabalhos de Sorace já referidos; Sorace \& Filiaci, 2006; Madeira et al., 2012), mas também em contexto de L1. Neste último caso, registam-se problemas no contexto de aquisição (cf., entre outros, Silva, 2015, 2018; Lobo \& Silva, 2016), que persistem na gramática adulta, facto evidenciado nos dados apresentados em 3.2 e já assinalado por Cardoso \& Magro (2013).

De forma sumária, os dados mostram que, nos dois contextos em comparação, se verificam os seguintes fenómenos:

(i) Violação da estratégia de minimização (vejam-se (4), de traduções, e (10), de produções autênticas em L1);

(ii) Utilização indevida de sujeitos nulos, conduzindo a interpretações não preferenciais ou inadequadas (vejam-se (5) e (6), de traduções, e (18) e (22), de produções autênticas em L1);

(iii) Seleção de expressões anafóricas inadequadas, com particular destaque para o uso de pronomes demonstrativos (vejam-se (7), de traduções, e (27), de produções autênticas em L1).

Embora se possa encontrar o mesmo tipo de problemas em ambos os contextos, observam-se, no entanto, algumas diferenças quanto às expressões anafóricas envolvidas. Em primeiro lugar, considere-se o pronome realizado nominativo de 3 . $^{\text {a }}$ pessoa (ele e suas variantes). Nas traduções analisadas, o recurso a esta forma foi frequente em contextos em que um sujeito nulo seria mais adequado por ser retomado um antecedente com proeminência estrutural, resultando, assim, em violações frequentes da estratégia de minimização. Pelo contrário, nos textos de escrita autêntica, não se assinalou qualquer problema no uso dessa forma pronominal em posição de sujeito. Ora, se tivermos em conta os dados de outras situações de contacto linguístico, como os de aquisição bilingue, de aquisição de L2 e de erosão linguística (Sorace 2000, 2003, 2011; Sorace \& Filiaci 2006; Madeira et al., 2012), bem como os de tradução inglês-italiano (Cardinaletti, 2004, 2005, 2012; Giusti, 2004), verificamos que os pronomes realizados são os que apresentam maiores problemas, com uma tendência para a sobreaceitação dos mesmos em contextos em que não são adequados ou preferenciais. Os dados das traduções confirmam esta tendência, o que parece apontar, neste caso, para interferência sintática da LP na LC: com efeito, o preenchimento desta posição é obrigatório em inglês, LP das traduções, sendo, portanto, recorrentes as formas nominativas, ao contrário do que se verifica em PE, que, sendo uma língua de sujeito nulo consistente, tende a evitar a realização do pronome sujeito (em conformidade como o princípio Evitar o

${ }^{3}$ Embora o número de textos correspondentes a traduções (7) seja menor do que o número de textos de produções escritas autênticas em L1 (50), o número total de palavras é próximo: cerca de 14.000, no primeiro caso; cerca de 17.500, no segundo. 
Pronome, de Chomsky 1981, ou Minimize a Estrutura, de Cardinaletti \& Starke 1999), desde que se encontrem reunidas as condições para retoma do antecedente adequado (cf. Gonçalves \& Colaço, 2019).

A ausência de formas nominativas de 3. . pessoa realizadas inadequadamente nos dados das produções escritas autênticas em L1 é, de certo modo, compensada por uma sobreutilização das formas dos pronomes demonstrativos, que dá origem a dois tipos de problemas: (i) violação da estratégia de minimização e/ou (ii) retoma do antecedente inadequado. Neste contexto, o recurso aos pronomes demonstrativos parece apontar para uma tendência para evitar a realização da forma nominativa, que, em posição de sujeito, dá origem a redundância. Nas traduções analisadas, encontra-se também representada esta estratégia de preenchimento da posição de sujeito, o que pode ser, de novo, interpretado como interferência sintática do inglês e, tal como nas produções escritas espontâneas, constituir uma forma de evitar o uso de formas nominativas. No entanto, o recurso a formas demonstrativas parece ter menor expressão nas traduções, facto que terá de ser confirmado em outros estudos, em que se utilize uma metodologia mais controlada.

Em segundo lugar, os dois tipos de dados distinguem-se quanto aos casos de incompatibilidade de traços morfológicos entre antecedente e anáfora, recorrentes no corpus de produções espontâneas e ausentes das traduções analisadas. Dado que as traduções têm como LP o inglês, língua em que a flexão de género, número e pessoa é consideravelmente menos rica do que em PE, seria expectável encontrar mais problemas desta natureza nesse contexto do que nas produções escritas autênticas em L1, o que seria facilmente explicado por interferência sintática. Esta diferença pode encontrar diversas explicações. Pensamos que a mais relevante é o tempo disponibilizado para as tarefas em questão: os autores das traduções recolhidas tiveram dois meses para realizar o seu trabalho, pelo que tiveram oportunidade de rever o texto, eventualmente eliminando alguns problemas resultantes de lapsos de escrita; pelo contrário, os estudantes que produziram os textos autênticos em L1 dispuseram de um tempo muito limitado, dado que esses textos eram parte integrante de uma prova de avaliação presencial que incluía outros itens. Efetivamente, julgamos que alguns casos assinalados como incompatibilidade de traços morfológicos entre o antecedente e a forma anafórica poderiam ter sido eliminados se o texto tivesse sido submetido a uma revisão atenta.

\section{Conclusão}

Neste trabalho, retomámos os dados apresentados em Gonçalves \& Colaço (2019), em que foram abordadas questões relacionadas com problemas na (re)construção de cadeias de referência no contexto da tradução de inglês para português identificados em textos produzidos por estudantes universitários.

Com base em ideias desenvolvidas por outros autores e baseadas noutras línguas, o fenómeno que, inicialmente, foi encarado como o resultado de um decalque de propriedades do inglês para o português foi reanalisado como decorrendo de um fenómeno mais geral de interferência linguística - nomeadamente, neste caso, de interferência da língua de partida na língua de chegada (cf., e.o., Cardinaletti, 2004, 2005, 2011; Giusti, 2004) -, que se manifesta relativamente a diversos aspetos linguísticos que se situam em áreas de interface entre a sintaxe e as componentes interpretativas da gramática, nomeadamente a semântica e a pragmática, que são consideradas particularmente vulneráveis e, por isso, potencialmente problemáticas.

Com o intuito de avaliar o impacto do contacto de línguas no comportamento linguístico dos falantes, concretamente no que diz respeito à seleção das formas anafóricas na posição de sujeito, os dados obtidos no contexto da tradução foram comparados com dados de L1 retirados de textos correspondentes a situações de escrita autêntica, a partir do corpus CUTe (cf. Cardoso et al., 2014). Esta comparação permitiu atestar a ocorrência de problemas do mesmo tipo em ambos os contextos, relacionados com a escolha das formas anafóricas, nomeadamente: (i) violação da estratégia de minimização; (ii) utilização indevida de sujeitos nulos, conduzindo a interpretações não preferenciais ou inadequadas; (iii) seleção de expressões anafóricas inadequadas, com particular destaque para o uso de pronomes demonstrativos. Tornou-se, no entanto, notória a 
presença de certas particularidades em cada um dos contextos, entre as quais se destaca, por um lado, no caso dos textos traduzidos, a tendência para a realização do sujeito por formas pronominais nominativas em contextos em que o antecedente é proeminente, e, portanto, que favorecem formas nulas, e, por outro lado, no caso dos textos autênticos produzidos na L1, um problema recorrente com o uso de pronomes demonstrativos, quer no que diz respeito à sua distribuição quer no que diz respeito à sua forma. Foi também de salientar, neste último contexto, a ocorrência de problemas de compatibilidade, em termos dos valores de traços morfológicos, entre a expressão anafórica e o seu antecedente. Embora tenha sido sugerida a hipótese de tais problemas resultarem de lapsos de escrita que não foram corrigidos devido às condições de produção dos textos, este é um aspeto que merecerá alguma atenção em trabalhos futuros.

O estudo realizado mostrou o interesse numa pesquisa mais aprofundada sobre esta questão que permita uma maior compreensão do impacto da situação de contacto de línguas característica da atividade tradutória no comportamento linguístico dos falantes relativamente à construção de cadeias de referência e, mais concretamente, à seleção das expressões nominais com valor anafórico. Para isso, torna-se fundamental reunir condições que viabilizem o uso de uma metodologia que permita uma comparação, com base em dados quantitativos, das produções dos mesmos falantes em ambos os contextos, tradução e produção autêntica em L1. Esta comparação permitirá obter resultados mais seguros quanto aos fatores que explicam as hesitações e as dificuldades que foram notadas neste trabalho.

\section{Referências:}

Ariel, Mira (1990) Accessing noun-phrase antecedents. London / New York: Routledge

Ariel, Mira (1996) Referring expressions and +/- coreference distinction. In Thornstein Fretheim \& Jeanette K. Gundel (orgs.) Reference and referent accessibility. Amsterdam: John Benjamins Publishing Company, pp. $13-35$.

Baker, Mona (1992) In other words. A coursebook in translation. New York: Routledge.

Baker, Mona (1993) Corpus linguistics and translation studies: implications and applications. In Mona Baker, Gill Francis \& Elena Tognini-Bonelli (orgs.) Text and technology: in honour of John Sinclair. Amsterdam/Philadelphia: Benjamins, pp. 233-250.

Baker, Mona (1996) Corpus-based Translation Studies: The challenges that lie ahead. In Harold Somers (org.) Terminology, LSP and Translation: Studies in Language Engineering, in Honour of Juan C. Sager. Amsterdam/Philadelphia: John Benjamins, pp. 175-186.

Blackwell, Sarah E. (2003) Implicatures in Discourse. The case of Spanish NP anaphora. Amsterdam/Philadelphia: John Benjamins.

Campos, Henriqueta da Costa \& M. Francisca Xavier (1991) Sintaxe e Semântica do Português. Lisboa: Universidade Aberta.

Cardinaletti, Anna (2004) La traduzione dei pronomi: interferenza sintattica e cambiamento linguistico. In Giuliana Garzone and Anna Cardinaletti (orgs.) Lingua, mediazione linmguistica e interferenza. Milano: Franco Angeli, pp. 129-150.

Cardinaletti, Anna (2005) La traduzione: un caso di attrito linguistico. In Anna Cardinaletti \& Giuliana Garzone (orgs.) L'italiano delle traduzioni. Milano: Franco Angeli, pp. 59-83.

Cardinaletti, Anna (2012) Ancora sull'italiano delle traduzioni. Altre Modernità, numero speciale: Traduzione e riscrittura, pp. 78-86.

Cardinaletti, Anna \& Michael Starke (1999) The typology of structural deficiency: A case study of three classes of pronouns. In Henk van Riemsdijk (org.) Clitics in the Languages of Europe. Berlin/New York: Mouton de Gruyter, pp. 145-233. 
Cardoso, Adriana \& Catarina Magro (2013) Problemas de coesão referencial na escrita académica em português. Comunicação proferida na $3^{\text {a }}$ Conferência Internacional em Gramática e Texto - GRATO 2013. Lisboa, FSCH-UNL.

Cardoso, Adriana, Catarina Magro, João Braz \& Teresa Nunes (2014) CUTe: Corpus of Portuguese Undergraduates' Texts. Um recurso para a investigação em escrita académica em português. In Textos Selecionados, XXIX Encontro Nacional da Associação Portuguesa de Linguística. Porto: APL, pp. 169-184.

Chomsky, Noam (1981) Lectures on Government and Binding. Foris: Dordrecht.

Chomsky, Noam (1995) The Minimalist Program. Cambridge, Mass.: The MIT Press.

Corpus CUTe. Disponível em: https://corpuscute.wixsite.com/cute/consulta

Figueiredo, Olívia (2000) A anáfora nominal em textos de alunos: a língua no discurso. Tese de doutoramento. Faculdade de Letras da Universidade do Porto.

Fox, Barbara A. (1987) Discourse structure and anaphora: Written and conversational English. Cambridge: Cambridge University Press.

Frawley, William (1984) Translation: literary, linguistic and philosophical perspectives. Delaware: University of Delaware Press.

Giusti, Giuliana (2004) Interferenza dell'inglese sulla posizione del soggetto in italiano: alcune considerazioni sulle traduzioni italiane di Harry Potter. In Giuliana Garzone \& Anna Cardinaletti (orgs.) Lingua, mediazione linguistica e interferenza. Milano: Franco Angeli, pp. 151-166.

Gonçalves, Anabela \& Madalena Colaço (2019) A coesão referencial em textos traduzidos do inglês para o português: a questão dos sujeitos nulos. Revista da Associação Portuguesa de Linguística 5, pp. 123-144.

Grice, Paul (1989) Studies in the way of words. Cambridge, MA: Harvard University Press. Gusmani, Roberto (1981) Saggi sull'interferenza linguistica I. Firenze: Casa Editrice Le Lettere.

Hatim, Basil \& Jeremy Munday (2004) Translation: An advanced resource book. New York: Routledge.

Hinds, John (1978) Anaphora in discourse. Edmonton: Linguistic Research Inc.

Hinds, John (1979) Organizational patterns in discourse. In Talmy Givón (org.) Discourse and syntax. London: Academic Press, pp. 135-157.

Hora, Katharine, Paula Luegi, Armanda Costa \& Marcus Maia (2019) Resolução de pronomes em posição de sujeito em orações completivas na retoma de antecedentes em SNs complexos: estudo comparativo entre português brasileiro e português europeu. Revista da Associação Portuguesa de Linguística 5, pp. 207-224.

Huang, Yan (1989) Anaphora in Chinese: Toward a pragmatic analysis. PhD Dissertation, University of Cambridge.

Huang, Yan (2000) Discourse anaphora: four theoretical models. Journal of Pragmatics 32, pp. 151-176.

Levinson, Stephen C. (1987) Minimization and conversational inference. In Jef Verschueren. \& Marcella Bertuccelli Papi (orgs.) The pragmatic perspective. Amsterdam/Philadelphia: John Benjamins, pp. 61-129.

Levinson, Stephen C. (1991) Pragmatic reduction of the Binding Condition revisited. Journal of Linguistics 27 , pp. 107-161.

Levinson, Stephen C. (1995) Three levels of meaning. In Frank R. Palmer (org.) Grammar and meaning. Cambridge: Cambridge University Press, pp. 90-115.

Lobo, Maria (2013) Dependências referenciais. In Raposo et al. (orgs.) Gramática do Português. Lisboa: FCG, pp. 2177-2227.

Lobo, Maria \& Carolina Silva (2016) Ambiguidade pronominal em orações adverbiais do português europeu: crianças vs. adultos. Revista da Associação Portuguesa de Linguística 2, pp. 319-338.

Luegi, Paula (2012) Processamento de sujeitos pronominais em Português: efeito da posição estrutural dos antecedentes. Tese de Doutoramento, Universidade de Lisboa.

Luegi, Paula, Armanda Costa \& Marcus Maia (2014) Processamento e interpretação de sujeitos nulos e plenos em português europeu e em português do Brasil. Cadernos de Letras da UFF 49, pp. 67-88. 
Madeira, Ana, M. Francisca Xavier \& Maria de Lourdes Crispim (2012) Uso e interpretação de sujeitos pronominais em português L2. Textos Selecionados, XXVII Encontro Nacional da Associação Portuguesa de Linguística. Lisboa: APL, pp. 376-397.

Mendes, Amália (2013) Organização textual e articulação de orações. In Raposo et al. (orgs.) Gramática do Português. Lisboa: FCG, pp. 1691-1755.

Newmark, Peter (1998) A textbook of translation. New York/London: Prentice Hall.

Oliveira, Fátima (1987) Cadeias anafóricas. Que referência? Revista da Faculdade de Letras: Línguas e Literaturas, pp. 125-136.

Silva, Carolina (2015) Interpretation of clitic, strong and null pronouns in the acquisition of European Portuguese. Tese de doutoramento, FCSH-Universidade Nova de Lisboa.

Silva, Carolina (2018) How Portuguese children interpret subject pronouns in complement clauses. Effects of mood selection and position of the antecedent. In Ana Lúcia Santos \& Anabela Gonçalves (orgs.) Complement clauses in Portuguese. Syntax and acquisition. Amsterdam/Philadelphia: John Benjamins, pp. 361-391.

Silva, Fátima (2001) Do possível e impossível em redenominação demonstrativa anafórica. In Isabel Margarida Duarte, Joaquim Barbosa, Sérgio Matos \& Thomas Hüsgen (orgs.) Encontro Comemorativo dos 25 Anos do Centro de Linguística da Universidade do Porto. Porto: CLUP, pp. 141-156.

Sorace, Antonella (2000) Differential effects of attrition in the L1 Syntax of near-native L2 speakers. In Catherine Howell, Sarah A. Fish \& Thea Keith-Lucas (orgs.) Proceedings of the $24^{\text {th }}$ Boston University Conference on Language Development. Somerville, MA: Cascadilla Press, pp. 719-725.

Sorace, Antonella (2002) Cambiamenti sintattici nell'italiano L1 di parlanti dell'inglese a livello avanzato. Comunicação apresentada ao congresso Italiano e inglese a confronto: problemi di interferenza linguistica, Università Ca’ Foscari di Venezia, 12-13 abril.

Sorace, Antonella (2003) Near nativeness. In Catherine J. Doughty \& Michael H. Long (orgs.) The handbook of second language acquisition. Oxford: Blackwell, pp. 130-151.

Sorace, Antonella (2005) Selective optionality in language development. In Leonie Cornips \& Karen P. Corrigan (orgs.) Syntax and variation. Reconciling the biological and the social. Amsterdam/Philadelphia: John Benjamins, pp. 55-80.

Sorace, Antonella (2011) Pinning down the concept of 'interface' in bilingualism. Linguistic Approaches to Bilingualism 1, pp. 1-33.

Sorace, Antonella \& Francesca Filiaci (2006) Anaphora resolution in near-native speakers of Italian. Second Language Research 22, pp. 339-368.

Teixeira, Joana (2016) (Re)thinking the Interface Hypothesis and its implications for language teaching. In Tilly Harrison, Ursula Lanvers \& Martin Edwardes (orgs.) Breaking theory: New directions in Applied Linguistics. Proceedings of the 48th Annual Meeting of the British Association for Applied Linguistics. London: Scitsiugnil Press, pp. 93-110.

Toury, Gideon (1995) Descriptive Translation Studies and Beyond. Amsterdam: John Benjamins.

Tsimpli, Ianthi, Antonella Sorace, Caroline Heycock, Francesca Filiaci, Maria Bouba (2003) Subjects in L1 attrition: evidence from Greek and Italian Near-Native Speakers of English. In Barbara Beachley, Amanda Brown \& Frances Conlin (orgs.) Proceedings of the $27^{\text {th }}$ Annual Boston University Conference in Language Development. Somerville, MA: Cascadilla Press, pp. 787-797.

Venuti, Lawrence (1995) The translator's invisibility: A history of Translation. London / New York: Routledge. Vinay, Jean-Paul \& Jean-Louis Darbelnet (1958) Stylistique comparée du français et de l'anglais. Méthode de traduction. Paris : Didier.

Weinreich, Uriel (1953) Languages in Contact. The Hague: Mouton. 